\title{
Structural and Textural Characterization of the Substrate and Coated Layer in an Industrial Galvannealed Interstitial-Free Steel
}

\author{
A. CHAKRABORTY, R.K. RAY, and S. SANGAL
}

DOI: $10.1007 / \mathrm{s} 11661-008-9648-5$

(c) The Minerals, Metals \& Materials Society and ASM International 2008

Erratum to: METALLURGICAL AND MATERIALS

TRANSACTIONS A

DOI: $10.1007 / \mathrm{s} 11661-008-9589-\mathrm{z}$

THERE is an error in the data presented in Figure 9 in the original article. The corrected Figure 9 is as follows:

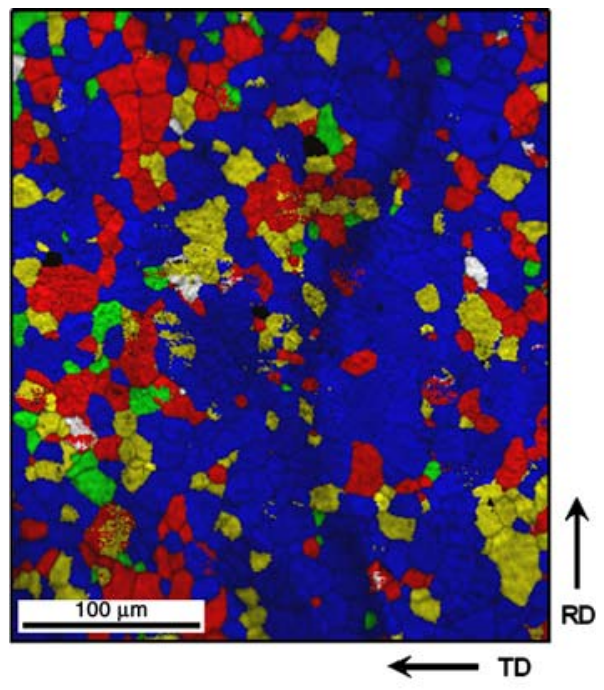

\begin{tabular}{|ccccc|}
\hline Color Code & Direction & Minimum & Maximum & $\%$ \\
\hline & $<111>\| N D$ & $0^{\circ}$ & $15^{\circ}$ & 62.4 \\
\hline & $<113>\| N D$ & $0^{\circ}$ & $15^{\circ}$ & 20.1 \\
$\square$ & $<313>\| N D$ & $0^{\circ}$ & $15^{\circ}$ & 13.0 \\
$\square$ & $<001>\| N D$ & $0^{\circ}$ & $15^{\circ}$ & 3.40 \\
\hline & $<101>\| N D$ & $0^{\circ}$ & $15^{\circ}$ & 0.30 \\
\hline
\end{tabular}

Fig. 9-Color-coded map of crystal directions of substrate steel.

A. CHAKRABORTY, Researcher, and R.K. RAY, Visiting Scientist, are with the Research and Development Division, Tata Steel, Jamshedpur PIN-831 007, India. Contact e-mail: ani chakra@ yahoo.com S. SANGAL, Professor, is with the Indian Institute of Technology, Kanpur PIN-208 016, India.

The online version of the original article can be found under doi: 10.1007/s11661-008-9589-z.

Article published online August 14, 2008 